\title{
Black (pyrogenic) carbon in soils and waters: a fragile data basis extensively interpreted
}

\author{
Jörg Gerke*
}

\begin{abstract}
Black (pyrogenic) carbon (BC) has its origin in incomplete combustion of organic matter. It is considered to be a stable fraction of soil organic carbon (SOC) accounting for a great proportion of SOC in many soils. The aim of this article is to verify the reliability of the three most widely applied methods to determine $B C$ in soils: the benzene polycarboxylic acid (BPCA) method, the UV/NMR method and the ${ }^{13} \mathrm{CNMR}$ method. All these methods strongly overestimate $\mathrm{BC}$ in soil and dissolved $B C$ in waters. The main reason for the overestimation can be attributed to the fact that these three methods measure the polycyclic aromatic carbon (PAC) present in BC. However, PAC structures are also a component of humic substances so that a part of humic $C$ is measured as $B C$. It can be concluded that the importance of $B C$ in soil and waters is strongly overestimated and should be critically reevaluated.
\end{abstract}

Keywords: Black (pyrogenic) carbon, Humic substances, Black carbon overestimation, Biochar, Soil organic carbon

\section{Introduction}

Today there is no consensus within the scientific community about the chemical forms of stable soil organic carbon (SOC) and about the mechanisms of preservation, reactions, and degradation of SOC, partly due to the complexity of forms and reactions in soil including chemical, biochemical, and biological reactions and partly due to the different points of view under which soil organic matter (SOM) is considered, e.g., soil fertility, or soil as a C sink or source.

High concentrations of SOC may be a main origin of soil fertility. The relation between SOC concentrations and soil fertility is not positive over the whole range of SOC concentrations since peaty soils may be less fertile than mineral soils with relatively high SOC concentrations. The effect of soil organic matter (SOM) on soil fertility strongly depends on the chemical forms of soil organic carbon [1]. Two developments in SOM research within the last three decades can be observed: an increasing focus on the biology of soil organic matter transformations, and the introduction of fire-affected (pyrogenic or black) carbon (BC) as an assumed main component of stable soil organic matter. Both drifts are accompanied by a reduced interest in soil humic substances chemistry and biochemistry or even by an attitude to ignore soil humic substances [2].

Both BC and humic substances are considered to constitute stable SOC pools in soils. This is of central relevance considering elevated $\mathrm{CO}_{2}$ levels in the atmosphere, which may be partly compensated by accumulation of organic carbon within stable soil fractions.

In this paper, a critical reevaluation of the methods and results of $\mathrm{BC}$ determination and quantification in soils and dissolved $\mathrm{BC}$ (DBC) in waters is presented, and conclusions are drawn with respect to the quantitative roles of $\mathrm{BC}$ and $\mathrm{DBC}$ in soils and waters, their possible contributions to climate changes mitigation, and the role of added BC/biochar application to improve soil fertility.

Gerke [3] already made some critical comments on the determination of $\mathrm{BC}$ in soils. The present paper is a strong extension including some important recent papers (Nakane et al. [4]; Zimmermann and Mitra [5]; Wagner et al. [6]) and especially Chang et al. [7] who showed that the most widely applied method to determine $\mathrm{BC}$-the BPCA method-is not specific for BC.

\footnotetext{
*Correspondence:
}

Rukieten, Germany 


\section{Black (pyrogenic) carbon in soil and its potential ecological relevance}

Black or pyrogenic carbon (BC) as fire-affected organic matter has its origin in incomplete combustion [8] and is considered to be a stable part of soil organic carbon (SOC) with a potential to mitigate the increase of atmospheric $\mathrm{CO}_{2}$ concentration [9].

The increasing importance of $\mathrm{BC}$ and of its manufactured form, biochar, within the scientific community is documented by Novotny et al. [10]. They counted the number of scientific articles on $\mathrm{BC}$ in the period between 2007 and 2014 and found an increase from 8500 to more than 18,000 papers a year till 2014 . For biochar, the respective numbers were very low in 2007 and increased to about 880 papers in 2014. One conclusion of these results may be that the rising number of $\mathrm{BC}$ papers helped to increase the interest in biochar, as a technical application of some types of black carbon to soil.

The present high-level interest in $\mathrm{BC}$ and biochar application to soil probably has its origin in studies which showed high concentrations of $\mathrm{BC}$ in tropical soils up to 300 (mg BC/g SOC) with BC being $30 \%$ of SOC [11, 12]. In European chernozems, values between 15 and $45 \%$ were reported [13] and interpreted in such a way that "Black chernozemic soils in central Europe originate from ancient biomass burning" [14], suggesting that BC is the most important SOC fraction in chernozemic soils. In the US agricultural soils, Skjemstad et al. [15] detected $\mathrm{BC}$ contents up to $35 \%$ of SOC. All these values represent indeed relatively high and significant proportions of $\mathrm{BC}$ of SOC. In the same vein, Ponomarenko and Anderson [16] found high BC contents in Canadian chernozemic soils. However, those authors were more careful and wrote about an organic fraction resistant to UV irradiation which is similar to char.

From the above-cited papers, it may be concluded that $\mathrm{BC}$ is an important part of SOC in these fertile soils and thus, the application of biochar may be a technique to improve soil fertility in general.

Probably the above-cited papers have induced extensive research on $\mathrm{BC}$ in soil and subsequently on biochar as soil fertilizer.

However, the methods to determine $\mathrm{BC}$ in soil have to be critically reevaluated.

Gerke [3] described some critics with respect to the methods used for the determination of $\mathrm{BC}$ in soils. Three recent papers $[4,5,7]$ now allow a conclusive description of the problems associated with the most common methods to determine $\mathrm{BC}$ in soils.

\section{Quantitative determination of BC in soils- frequently used methods, pitfalls, and errors}

After the publication of Schmidt et al. [17] who compared several common methods to determine $\mathrm{BC}$ in soils, a critical revaluation of data and interpretation of $\mathrm{BC}$ in soils gained before was warranted. This is especially remarkable, because the main authors who found very high $B C$ values in several soils also contributed to the comparative analysis by Schmidt et al. [17].

Schmidt et al. [17] compared six methods to determine $\mathrm{BC}$ in eight Australian soils, four of them including thermal oxidation of SOC by heating at temperatures ranging from 340 or $375{ }^{\circ} \mathrm{C}$ with or without preextraction and/or chemical preoxidation. The organic residue after thermal oxidation was attributed to be $\mathrm{BC}$.

We here only compare the commonly used method with a maximum temperature of $375^{\circ} \mathrm{C}$ including preextraction/oxidation (CTO 375) with two other methods. The CTO 375 method gave values up to $7.5(\mathrm{mg} \mathrm{BC} / \mathrm{g}$ $\mathrm{SOC}$ ). [The $340{ }^{\circ} \mathrm{C}$ methods gave higher values between 7.0 and $23.4(\mathrm{mg} \mathrm{BC} / \mathrm{g} \mathrm{SOC})$ probably because not all of the non-BC was oxidized at lower temperatures]. The remaining two methods have been widely applied and delivered high $\mathrm{BC}$ values. The BPCA method after Glaser et al. [18] uses oxidation of SOC. The formed benzene polycarboxylic acids (BPCAs) are considered as a measure for $\mathrm{BC}$ in soil and are quantified by chromatographic methods. A factor then relates BPCA yield to BC content in soils.

Using the BPCA method, Schmidt et al. [17] found BC values in the same eight Australian soils between 37.2 and 131.1 ( $\mathrm{mg} \mathrm{BC} / \mathrm{g}$ SOC), the $\mathrm{BC}$ values determined with BPCA methods being higher by a factor of 10-15 than the values determined with the CTA 375 method.

The last method in this comparison consists of a combination of oxidation of SOC by UV-irradiation and the determination of $\mathrm{BC}$ in the residues by solid ${ }^{13} \mathrm{C}$ NMR spectroscopy assuming aryl $\mathrm{C}$ signals being distributed between lignin and BC [19]. The UV/NMR method gave the by far highest $\mathrm{BC}$ values in six of the eight Australian soils which were higher up to a factor of $>500$ than the CTA 375 values [17].

The $\mathrm{BC}$ values determined by the CTA 375 method were the by far lowest values. However, there are two reasons, as to why $\mathrm{BC}$ values in soils may be overestimated even by the CTA 375 method:

1. Simpson and Hatcher [20] found that during the thermal treating, pyrogenic artifacts were produced which were then determined as BC.

2. Differential thermal gravimetric analysis showed that the main weight loss of charcoal during heating was > $400{ }^{\circ} \mathrm{C}$, which was similar to lignin [21]. From these 
data, it may be concluded that a part of soil lignin is determined as BC with the CTA 375 method. This fact may be the reason, why Edmondson et al. [22] differentiated $\mathrm{BC}$ in soil by differential thermogravimetric analysis, over the region between 200 and $470{ }^{\circ} \mathrm{C}$ attributing to "ecosystem-derived organic carbon" and the region between 470 and $600{ }^{\circ} \mathrm{C}$ attributing to $\mathrm{BC}$.

In some cases, the $\mathrm{BC}$ values may be overestimated with the CTA 375 method, but the BPCA and the UV/ NMR methods probably will strongly overestimate $\mathrm{BC}$. This is the main result of the comparative study of Schmidt et al. [17].

The reasons for the overestimation of BC by the BPCA method now can clearly be described.

Brodowski et al. [23] showed that the BPCA method described by Glaser et al. [18] overestimates BC up to $90 \%$. They attributed this failure to the $\mathrm{HCl}$ pretreatment which they substituted. Kappenberg et al. [24] showed for the modification of the BPCA method that only BPCA with penta- or hexacarboxylic acids should be used as markers for $\mathrm{BC}$, and other BPCAs may originate from non-BC materials.

Glaser et al. [18] stated that they investigated, during the development of the original BPCA method, whether humic substances can be oxidized to BPCAs during the oxidation process and came to the conclusion that humic substances do not interfere with the $\mathrm{BC}$ analysis. However, they did not investigate soil humic acids. Instead, they used polyphenol polymerization products from ground apple, Maillard reaction products from arginine and fructose, and relatively fresh incubation residue of barley straw. They did not investigate humic substances, from which it is known that they can be oxidized to BPCAs [25, 26]. During the development of the BPCA method, there was an urgent need to test whether BPCAs are formed from humic substances during the BC analysis. This was avoided by Glaser et al. [18]. Those authors defined some reaction products of straw and apples as representatives of soil humic substances. Without any experimental proof, they stated that humic substances do not interfere with the $\mathrm{BC}$ analysis (e.g., [11]).

The work-which Glaser et al. [18] avoided-was done by Chang et al. [7] in their excellent paper. They tested the BPCA method on three soil samples and for some materials including fulvic acid, humic acid, lignin, and humic acids extracted from the three soil samples. By means of sequential removal of organic carbon fractions in the soil samples, Chang et al. [7] showed that humic substances contributed between 71.8 and $82.6 \%$ to the BPCAs formed during analysis which was performed according to [23]. In the same soil, samples BC, as the residual fraction in the extraction sequence, contributed between 2.4 and $10.1 \%$ to the BPCA formed. Chang et al. [7] also showed that humic acid from non-pyrogenic origin resulted in high BPCA activity after oxidation performed according to [23]. They simply showed for the three soil samples that after the extraction of humic substances with $\mathrm{NaOH}$, the BPCA yield after oxidation was reduced to between 71 and 83\% [7]. All these analytical procedures should have been conducted by Glaser et al. [18] during the development of the BPCA method to confirm a possible effect of soil humic substances on the BPCA yield.

Mature humic substances with polycyclic aromatic carbon (PAC) strongly contribute to the formation of BPCA [7]. Chang et al. [7] showed that mainly B5CA and B6CA substances were formed from humic substances, which is in contrast to the results of Kappenberg et al. [24] who recommended these BPCAs as indicators for BC. Chang et al. [7] concluded thus: "...The assignment of BPCAs to BC should be avoided."

In their paper, Chang et al. [7] also found that fulvic acid and lignin showed low BPCA contents after oxidation. Bostick et al. [27] showed that compost, oak biomass, and grass biomass gave very low BPCA yields when using the method of Brodowski et al. [23]. Both results support the view that mature soil humic substances, and not fresh degradation products and newly formed SOC (humic precursors according to [28, 29]), show BPCA activity after oxidation.

We may conclude thus: measurements of $\mathrm{BC}$ in soil with the BPCA method in its variations will strongly overestimate BC if humic substances are present.

The UV/NMR method after Skjemstad et al. [19] also overestimates $\mathrm{BC}$ which may explain the extremely high $\mathrm{BC}$ values for this method in the comparative study to Schmidt et al. [17]. This may be due to only partial destruction of non-BC carbon in soil, mainly humic substances which were shown to be resistant to UV irradiation (e.g., [30] and references therein). Novotny et al. [10] formulated the same argument on the rejection of the UV/NMR method for the determination of soil BC as follows: "Removal ... of non-pyrogenic $\mathrm{C}$ depends on the oxidation intensity which is overall lowest in the case of photooxidation...."

It seems that the UV/NMR method to detect $\mathrm{BC}$ in soil had been abandoned after 2002 with the exception of a ring trial [31] where it was used probably for comparison purposes.

The scientific $\mathrm{BC}$ community is obviously aware of the overestimation of $\mathrm{BC}$ by the method of Skjemstad et al. [19] and the original BPCA method of Glaser et al. [18], at least after the publication of the papers of Schmidt et al. [17] and Brodowski et al. [23]. 
However, BC data collected with both methods are still used long time afterwards to emphasize the role of $\mathrm{BC}$ in soil (among others: [2, 14, 32-43]).

For example, Solomon et al. [38] wrote thus: "...biomass-derived $\mathrm{BC}$ seems the main precursors of these highly refractory polyaromatic structures. This conclusion concurs with the suggestions of ... Glaser et al. [11]." The values of Glaser et al. (here [11]) on BC contents of Amazonian soils were very high (>30\% BC) mainly because of the use of the strongly $\mathrm{BC}$ overestimating method introduced by Glaser et al. [18]. A paper which summarized as a main result that highly refractory aryl$\mathrm{C}$ is the key for chemical recalcitrance and assumed that the origin is from biomass-derived $\mathrm{BC}$ ignores the overestimation of their single reference for high $B C$-values in Amazonian dark earths, i.e., the paper of Glaser et al. [11]. And even 8 years later, Lehmann and Kleber [2] referred to Solomon et al. [38] by stating that thermally altered carbon from vegetation fires are found in most soils, are polyaromatic, and typically extractable in alkaline solution. Lehmann and Kleber could have known by 2015 that the $\mathrm{BC}$ contents in soils measured with the UV/NMR or the first version of the BPCA method after [18] are not reliable.

Meanwhile solid-state ${ }^{13} \mathrm{C}$ NMR has been used as a method to determine directly $\mathrm{BC}$ in soils. Aromatic $\mathrm{C}$ NMR signals are assigned to $\mathrm{BC}$ or lignin, and humic substances have been ignored for the quantitative interpretation of the NMR spectra [42-46]. However, aromatic $\mathrm{C}$ and PAC are present in soil humic substances [7, $25,28,47-52]$. Some of the humic substances $C$ will be determined as BC. Cusack et al. [42] gave an explanation for their procedure to ignore humic substances in soils: "Historically, humic material was thought to consist of large polymers containing aromatic compounds created via condensation reactions during microbial decomposition [1]. However the importance of the reactions and neoformation of super-molecules has been questioned [53]; recent analyses suggest that alkali-extractable SOC is dominated by biological molecules...."

This statement of Cusack et al. [42] is wrong for at least two reasons. First, humic substances as polymers are initially formed by polymerization reactions of mainly phenolic radicals, and condensation reactions may subsequently be important [3]. Second, a new view on humic substances is largely based on the work of Piccolo [54, 55 ] and his coworkers who postulated a supramolecular structure of humic substances. Piccolo et al. [56], Cozzolino and Piccolo [57], and Nuzzo and Piccolo [58] showed that the supramolecular structure could react to humic polymers by adding peroxidases or catalysts, indicating that sometimes or often the transformation of humic supramolecules to humic polymers is restricted by the concentration of substrates (phenolic monomers) or catalysts (peroxidases, phenolases, $\mathrm{OH}^{-}$radicals, or $\mathrm{Mn}, \mathrm{Fe}$ ) or both (see also [3]). Thus, Piccolo and coworkers emphasize the biochemical or chemical formation of humic substances in soil, too. To ignore humic substances in soil is not in the line with Sutton and Sposito [53] and Piccolo and coworkers. The direct determination of $\mathrm{BC}$ in soil by means of ${ }^{13} \mathrm{C}$ NMR spectroscopy assuming that no humic substances are present is not justified. Additional support for the rejection of ${ }^{13} \mathrm{C}$ NMR spectroscopy to determine soil $\mathrm{BC}$ comes from Zimmermann and Mitra [5]. They plotted the content of SOC against BC in soils and used the data of Reisser et al. [59] who conducted a literature-based inventory of pyrogenic carbon in soils. The linear correlation coefficient for the relation between $\mathrm{BC}$ weight and $\mathrm{SOC}$ weight was 0.93 for the determination of $\mathrm{BC}$ by ${ }^{13} \mathrm{C}$ NMR indicating a strong correlation between the two parameters. The correlation coefficient between BC and SOC for the BPCA method was also very high with 0.77 . Zimmermann and Mitra [5] concluded for the BPCA and NMR methods as follows: "that these methods may have the greatest likelihood for artifacts that misidentify pyrC." Meanwhile ${ }^{13} \mathrm{C}$ NMR determination of $\mathrm{BC}$ in soil is used to calibrate $\mathrm{BC}$ determination by mid-infrared spectroscopy [60]. If, however, the calibration method is not reliable, then the determination of BC by MIR spectroscopy has no basis.

Waggoner et al. [61] showed by adding hydroxyl radicals, e.g., by Fenton reagent (FeII salt and $\mathrm{H}_{2} \mathrm{O}_{2}$ ) to ligningenerated polycyclic aromatic carbon species-this led DiDonato et al. [51] to the conclusion-that condensed aromatic compounds are a central part of soil humic substances. It, however, should be noted that Ziechmann ([28], p. 148-153) already described polycyclic aromatic structures in humic substances induced by hydroxyl radicals.

One conclusion is that with the aid of the most applied methods to determine $\mathrm{BC}$ in soil, the BPCA, the NMR, and the UV/NMR method, a more or less important proportion of soil humic substances, mainly polycyclic aromatic carbon, is determined as $\mathrm{BC}$ which will strongly overestimate $\mathrm{BC}$ in soil. It should be noted that in the CTO 375 method, no correlation between SOC and BC was found [5]. Reisser et al. [59] showed that the CTO 375 method yielded average $\mathrm{BC}$ values of about $5 \%$, the BPCA method an average of about $10 \%$ of $\mathrm{BC}$, and the NMR method and the UV/NMR method averages of about $15 \%$ of $\mathrm{BC}$ related to SOC. The determination of non-pyrogenic $C$ in soil as $B C$ is probably the reason for the close relation between $\mathrm{BC}$ and $\mathrm{SOC}$, and among the soil organic $\mathrm{C}$ fractions, $\mathrm{PAC}$ as constituent humic substances may be preferentially determined as BC. 


\section{Black carbon and soil fertility-the role of biochar}

The strong overestimations of $\mathrm{BC}$ by the BPCA, the NMR, and the UV/NMR methods may lead to an overestimation of the role of $\mathrm{BC}$ for soil fertility. From the experimental basis of high $\mathrm{BC}$ contents the increasing interest in biochar to improve soil fertility was derived. If fertile Amazonian soils, fertile European chernozemic soils and US agricultural soils exhibit high BC contents, then the application of biochar may improve fertility of many other soils (e.g., [10, 35, 62-64]).

The terra preta soil profile described by Glaser et al. [11] is not necessarily related to BC but may have its origin in the incorporation of high quantities of organic matter within restricted areas leading to an accumulation of nutrients and an increased formation of stable humic substances with PAC as component. The results of Chang et al. [7] strongly support such an interpretation.

The role of biochar application for soil fertility was recently reviewed by Jeffery et al. [64] by means of a meta-analysis. In temperate soils, the application of biochar depressed yield around $3 \%$ on average, whereas in tropical soils. yield was increased by biochar about $25 \%$ on average at median application rates of $30 \mathrm{t} / \mathrm{ha}$ or $15 \mathrm{t} /$ ha to temperate or tropical soils, respectively. The effects of biochar on plant yield were both a liming effect and a nutritional effect. In a previous paper, Jeffery et al. [62] found also an increase of water-holding capacity which had a positive effect on plant yield besides liming effects and a nutrient effect of applied biochar. Considering their results of the meta-analysis, Jeffery et al. [64] summarized: "However in the light of this comprehensive analysis, the widespread hype of biochar use for crop yield effects must be questioned."

The conclusion of Jeffery et al. [64] is not astonishing regarding the origin of the "hype"-false data on BC in fertile soils.

Three main problems concerning the effect of biochar on plant yield may be mentioned here:

1. Nutrient losses during the biochar production, e.g., of nitrogen should be considered.

2. In experiments which aim to quantitate the effect of biochar on plant yield, the question of the control is seldom discussed. The effect of the charred material on yield should be compared with composts produced from the same materials.

3. Possible toxic effects of biochar compounds, e.g., polycyclic aromatic hydrocarbons should be considered in more detail. The negative yield effect of biochar on soils of temperate regions as reported by Jeffery et al. [64] may be due to toxic effects.
The questions remain therefore whether or not the yield effects of biochar on tropical soils, the liming, and nutrient effects can be better achieved by calcareous materials and other fertilizers, e.g., composts or mineral fertilizers; and whether or not the water-holding capacity of soils can be better increased by compost from the same source which otherwise is pyrolyzed to biochar.

\section{Biochar application to soil and the effect of BC on climate change}

Another goal of biochar application to soil is to introduce stable organic carbon to mitigate the increase of atmospheric $\mathrm{CO}_{2}$ concentration.

The problem associated with these considerations is that the actual concentrations of $\mathrm{BC}$ in soil are largely unknown due to the application of non-reliable methods for the $\mathrm{BC}$ determination, as described in the previous sections.

For example, Lorenz and Lal [9] reported soil concentrations up to $80 \%$ of $\mathrm{BC}$, as related to SOC in surface soils. The cited source for this high value is Krull et al. [65] who, however, showed no such high value which instead probably comes from Preston and Schmidt [34] or Eckmeier et al. [37] who themselves reported this value citing the paper of Ponomarenko and Anderson [16]. However, all these cited authors described their data in such a way that up to $60 \%$ of organic $C$ in soil and up to $80 \%$ in some soil fractions were resistant to UV irradiation and that the NMR spectra were consistent with the existence of char. Beside the already collected arguments questioning the determination of soil $\mathrm{BC}$ by the UV/ NMR method, the citation of the results of Ponomarenko and Anderson [16] by Preston and Schmidt [34] and Eckmeier et al. [37] in their reviews is not justified.

If the $\mathrm{BC}$ content of soils is generally much lower than that is reported, then the persistence of $\mathrm{BC}$ may be lower than that is assumed, and it may be concluded that the application of biochar to soils must be reconsidered with respect to climate change mitigation even under the assumption that biochar added to soil reacts similar to soil BC. Lorenz and Lal [9] hypothesized that surfaceapplied biochar must be translocated to subsoil layers to achieve the storage of organic carbon for hundreds to thousands of years.

The experimental verification for such hypothesis requires accurate $\mathrm{BC}$ determination in soils which is obviously lacking.

\section{Dissolved black carbon (DBC)}

Black carbon losses from soil will probably reduce the BC stability and will decrease the ability of soils to represent a carbon sink via $\mathrm{BC}$ accumulation. The formation of dissolved black carbon (DBC) may lead to black 
carbon leaching from soils at considerable rates as suggested by Jaffe et al. [66]. However, in their paper, the BC determination in waters was conducted after Dittmar [67] who used the BPCA method and, similar to Glaser et al. [18], ignored humic substances as potential interfering material for the analysis. Recently, Nakane et al. [4] showed that Suwannee River Humic acid II yielded a BPCA-carbon recovery between 5 and 6\% supporting the role of river humic substances for the $\mathrm{BC}$ determination in waters by the BPCA analysis. The concentrations of humic substances in various rivers are high and accounted for between 50 and $80 \%$ of the dissolved organic carbon (e.g., [68-72]).

Wagner et al. [6] showed in their review on DBC a close relation between DBC and dissolved organic carbon (DOC). They explained this relation by the physicochemical affinity of both constituents to each other or/and by similar mechanisms of mobilization and stabilization for DBC and DOC. Similar arguments on the close relation between soil $\mathrm{BC}$ and SOC contents were put forth by Reisser et al. [59] and Zimmermann and Mitra [5]. Wagner et al. [6] described also a close relation between DBC and chromophoric DOC (CDOC) in arctic rivers which is aromatic rich. In another universe, this fraction may be named dissolved humic substances. However, Wagner et al. [6] did not even mention the possibility that CDOM is oxidized to BPCAs during the DBC analysis, which may have explained $D B C$ values obtained in their review. For example, they reported that peat-influenced waters had high DOM concentrations and high DBC concentrations up to $2.8(\mathrm{mg} / \mathrm{l})$. Humic substances in peaty soils may account for $30 \%$ of peat dry matter ([48], p. 86) and may contribute to high DOM and DBC values in peat-affected waters. With the data on BPCA recovery of Suwannee humic acid II of 5-6\% C [4] probably most of the BPCA-measured DBC can be explained by humic substances in Table 1 by Wagner et al. [6] assuming that dissolved organic carbon is similarly oxidized to BPCAs compared to the humic acid of Nakane et al. [4].

\section{Interactions of humic substances and BC in soils}

One simple assumption for the $\mathrm{BC}$ determination in soil by the reviewed chemical methods is that $\mathrm{BC}$ is relatively independent of other soil constituents.

Wagner et al. [73] proposed molecular structures for dissolved black carbon (DBC) which consists of various polycyclic aromatic carbon (PAC) molecules with varying contents of phenol, carbonyl, or carboxylic groups. The higher the contents of the latter groups the higher the water solubility of the $\mathrm{BC}$ molecules is. $\mathrm{BC}$ at the soil solid phase will possess a few of these hydrophilic groups which make the reaction with hydrophobic regions of soil humic substances more probable. Piccolo $[54,55]$ and coworkers, and Piccolo and Conte [74] consider humic substances as relatively small molecules with a supramolecular structure stabilized mainly by hydrophobic forces thereby creating molecular associations of relatively high apparent molecular weight. The hydrophobic surfaces of the humic molecules adsorb, bind, and absorb BC into the humic framework. Simultaneously, BC may be bound to humic substances via metal bridges, mainly Fe(III) or $\mathrm{Al}(\mathrm{III})$ or electron donor-acceptor complexes ([3], Fig. 4).

The probable high affinity of soil $\mathrm{BC}$ to soil humic substances is relevant for the determination of $\mathrm{BC}$ in soils. Each of the methods to determine $\mathrm{BC}$ which were described above assume that no humic substances with polycyclic aromatic carbon exist in soil. The overestimation of soil $\mathrm{BC}$ following this wrong assumption is expected. If soil BC contents are relatively low, e.g., around some percent as suggested by the values of the CTA 375 method [59], then the question is that of the behavior of the soil humic substances incorporating $\mathrm{BC}$ and not of the $\mathrm{BC}$ as a single organic fraction in soils.

\section{Conclusions}

The most widely applied methods to determine black/ pyrogenic carbon in soil (BPCA method, UV/NMR method ${ }^{13} \mathrm{C}$ NMR spectroscopy) strongly overestimate black carbon in soils and dissolved black carbon in waters. The main reason for the overestimation is that polycyclic aromatic carbon as part of the humic substances is determined as black carbon. There is an urgent need to improve the determination of $\mathrm{BC}$ in soils and waters. The determination should consider the probable strong interaction between $\mathrm{BC}$ and humic substances or incorporation of $\mathrm{BC}$ into the humic frame.

\section{Abbreviations}

SOC: soil organic carbon; BC: black carbon; PAC: polycyclic aromatic carbon; BPCA: benzene polycarboxylic acid; DBC: dissolved black carbon; DOM: dissolved organic matter; DOC: dissolved organic carbon.

\section{Authors' contributions}

The author read and approved the final manuscript.

\section{Acknowledgements}

This paper is dedicated to the late Prof. Dr. Wolfgang Ziechmann who introduced the author into the chemistry of humic substances.

\section{Competing interests}

The author declares that he has no competing interests.

Availability of data and materials

All data analyzed or generated are included in this publication.

Funding

No funding. 


\section{Publisher's Note}

Springer Nature remains neutral with regard to jurisdictional claims in published maps and institutional affiliations.

Received: 17 January 2019 Accepted: 15 April 2019

Published online: 02 July 2019

\section{References}

1. Stevenson FJ. Humus chemistry. Genesis, composition, reactions. 2nd ed. New York: Wiley; 1994.

2. Lehmann J, Kleber M. The contentious nature of soil organic matter. Nature. 2015;528:61-8.

3. Gerke J. Concepts and misconceptions of humic substances as the stable part of soil organic matter: a review. Agronomy. 2018;8:76.

4. Nakane M, Ajioka T, Yamashita Y. Distribution and sources of dissolved black carbon in surface waters of the Chukchi sea, Bering sea, and the north Pacific ocean. Front Earth Sci. 2017;5:34.

5. Zimmerman AR, Mitra S. Trial by fire: on the terminology and methods used in pyrogenic organic carbon research. Front Earth Sci. 2017:5:95.

6. Wagner S, Jaffe R, Stubbins A. Dissolved black carbon in aquatic ecosystems. Limnol Oceanogr Lett. 2018;3:168-85.

7. Chang Z, Tian L, Li F, Zhou Y, Wu M, Steinberg Ch EW, Dong X, Pan B, Xing B. Benzene polycarboxylic acid - a useful marker for condensed organic matter, but not for only pyrogenic black carbon. Sci Total Environ. 2018;626:660-7.

8. Goldberg ED. Black carbon in the environment. New York: Wiley; 1985

9. Lorenz K, Lal R. Biochar application to soil for climate change mitigation by soil organic carbon sequestration. J Plant Nutr Soil Sci. 2014;177:651-70.

10. Novotny EH, Maia CMBDF, Carvalho MTDM, Madari BE. Biochar: pyrogenic carbon for agricultural use - a critical review. Revista Brasileira de Ciência do Solo. 2015;39:321-44.

11. Glaser B, Haumeier L, Guggenberger G, Zech W. The terra preta phenomenon: a model for sustainable agriculture in the humid tropics. Naturwissenschaften. 2001;88:37-41.

12. Glaser B, Guggenberger $G$, Zech W. Black carbon in sustainable soils of the Brazilian Amazonian region. In: Swift RS, Spark KM, editors. Understanding and managing organic matter in soils, sediments and waters. St Paul: International Humic Substances Society; 2001. p. 359-64.

13. Schmidt MWI, Skjemstad JO, Gehrt E, Kögl-Knabner I. Charred organic carbon in German chernozemic soils. Eur J Soil Sci. 1999:50:351-65.

14. Schmidt MWI, Skjemstad JO, Jäger C. Carbon isotope geochemistry and nano morphology of soil black carbon: black chernozemic soils in central Europe originate from ancient biomass burning. Glob Biogeochem Cycles. 2002;16:1123-31.

15. Skjemstad JO, Reicosky DC, Wilts AR, Mcgowan JA. Charcoal carbon in U.S. agricultural soils. Soil Sci Soc Am J. 2002;66:1249-55.

16. Ponomarenko EV, Anderson DW. Importance of charred organic matter in black chernozem soils of Saskatchewan. Can J Soil Sci. 2001;81:285-97.

17. Schmidt MWI, Skjemstad JO, Czimczik Cl, Glaser B, Prentice KM, Gelinas Y, Kuhlbusch TA. Comparative analysis of black carbon in soils. Glob Biogeochem Cycles. 2001;15:163-7.

18. Glaser B, Haumeier L, Guggenberger G, Zech W. Black carbon in soils: the use of benzenecarboxylic acids as specific markers. Org Geochem. 1998;29:811-9.

19. Skjemstad JO, Taylor JA, Smernik RJ. Estimation of charcoal (char) in soils Commun Soil Sci Plant Anal. 1999:30:2283-98.

20. Simpson MJ, Hatcher PG. Overestimates of black carbon in soils and sediments. Naturwissenschaften. 2004;91:436-40.

21. Laird DA, Chappell MA, Martens DA, Wershaw RL, Thompson M. Distinguishing black carbon from biogenic humic substances in soil clay fractions. Geoderma. 2008;143:115-22.

22. Edmondson JL, Stott I, Potter J, Lopez-Capel E, Manning DAC, Gaston KJ Leake JR. Black carbon contribution to organic carbon stocks in urban soils. Environ Sci Technol. 2015;49:8339-46

23. Brodowski S, Rodionow A, Haumeier L, Glaser B, Amelung W. Revised black carbon assessment using benzene polycarboxylic acids. Org Geochem. 2005:36:1299-310.
24. Kappenberg A, Bläsing M, Lehndorff E, Amelung W. Black carbon assessment using benzene polycarboxylic acids: limitations for organic rich matrices. Org Geochem. 2016;94:47-51.

25. Schnitzer M. Humic substances: chemistry and reactions. In: Schnitzer M, Kahn SU, editors. Soil organic matter. New York: Elsevier; 1978. p. 1-64.

26. Schnitzer M, Calderoni G. Some chemical characteristics of paleosol humic acids. Chem Geol. 1985:53:175-84.

27. Bostick KW, Zimmermann AR, Wozniak AS, Mitra S, Hatcher PG. Production and composition of pyrogenic dissolved organic matter from a logical series of laboratory-generated chars. Front Earth Sci. 2018;6:43.

28. Ziechmann W. Huminstoffe. Weinheim: Verlag Chemie; 1980.

29. Ziechmann W. Humic substances. Mannheim: BI-Wissenschaftsverlag; 1994.

30. Hermann R, Gerke J, Ziechmann W. Photodegradation of the surfactants $\mathrm{Na}$-dodecylbenzenesulfonate and dodecylpyridinium-chloride as affected by humic substances. Water Air Soil Pollut. 1997:98:43-55.

31. Hammes, et al. Comparison of quantification methods to measure firederived (black/elemental) carbon in soils and sediments using reference materials from soil, water, sediment and the atmosphere. Glob Biochem Cycles. 2007;21:1-18

32. Forbes MS, Raison RJ, Skjemstad JO. Formation, transformation, and transport of black carbon (charcoal) in terrestrial and aquatic ecosystems. Sci Total Environ. 2006;370:190-206.

33. Lehmann J, Rondon M. Biochar soil management on highly weathered soils in the humid tropics. In: Uphoff N, editor. Biological approaches to sustainable soil systems. Boca Raton: CRC Press; 2006. p. 517-30.

34. Preston CM, Schmidt MWI. Black (pyrogenic) carbon: a synthesis of current knowledge and uncertainties with special consideration of boreal regions. Biogeosciences. 2006:3:397-420.

35. Glaser B. Prehistorically modified soils of central Amazonia: a model for sustainable agriculture in the twenty-first century. Philos Trans R Soc Lond B Biol Sci. 2007;362:187-96.

36. Lehmann J. Bio-energy in the black. Front Ecol Environ. 2007:5:381-7.

37. Eckmeier E, Gerlach R, Gehrt E, Schmidt MWI. Pedogenesis of chernozems in central Europe-a review. Geoderma. 2007;139:288-99.

38. Solomon D, Lehmann J, Thies J, Schäfer T, Liang B, Kinyangi J, Neves E, Petersen J, Luizao F, Skjemstad J. Molecular signature and sources of biochemical recalcitrance of organic $C$ in Amazonian dark earths. Geochim Cosmochim Acta. 2007;71:2285-98.

39. Flessa $H$, Amelung W, Helfrich M, Wiesenberg GLB, Gleixner G, Brodowski S, Rethemeyer J, Kramer Ch, Grootes PM. Storage and stability of organic matter and fossil carbon in a Luvisol and Phaeozem with continuous maize cropping: a synthesis. J Plant Nutr Soil Sci. 2008;171:36-51.

40. Hammes K, Torn MS, Lapenas AG, Schmidt MWI. Centennial black carbon turnover observed in a Russian steppe soil. Biogeosciences. 2008;5:661-83

41. Schmidt MWI, Torn MS, Abiven S, Dittmar T, Guggenberger G, Janssens IA, Kleber M, Kögl-Knabener I, Lehmann J, Manning DAC, Nannipieri P, Rasse DP, Weiner S, Trumbore SE. Persistence of soil organic matter as an ecosystem property. Nature. 2011;478:49-56.

42. Cusack DF, Chadwick OA, Hockaday WC, Vitousek PM. Mineralogical controls on soil black carbon preservation. Glob Biogeochem Cycles. 2012:26:GB2019.

43. Mao J-D, Johnson RL, Lehmann J, Olk DC, Neves EG, Thompson ML, Schmidt-Rohr K. Abundant and stable char residues in soils: implications for soil fertility and carbon sequestration. Environ Sci Technol. 2012;46:9571-6.

44. Nelson PN, Baldock JA. Estimating the molecular composition of a diverse range of natural organic materials from solid-state ${ }^{13} \mathrm{C}$ NMR and elemental analysis. Biogeochemistry. 2005;72:1-34.

45. Fang X, Chua T, Schmidt-Rohr K, Thompson ML. Quantitative ${ }^{13} \mathrm{C}$ NMR of whole and fractionated lowa mollisols for assessment of organic matter composition. Geochim Cosmochim Acta. 2010;74:584-98.

46. Baldock JA, Sandermann J, MacDonald LM, Puccini A, Hawke B, Szarvas S, McGowan J. Quantifying the allocation of soil organic carbon to biologically significant fractions. Soil Res. 2013:51:561-76.

47. Schulten HR, Schnitzer M. A state of art structural concept for humic substances. Naturwissenschaften. 1993:80:29-30.

48. Ziechmann W. Huminstoffe und ihre Wirkungen. Heidelberg: Spectrum Akademischer Verlag; 1996 
49. Ikeya K, Higake T, Arai S, Watanabe A. Size distribution of condensed aromatic rings in various soil humic acids. Org Geochem. 2011;42:55-61.

50. Erro J, Urrutia O, Baigorri R, Fuentes M, Zamerreno G, Garcia-Mina JM. Incorporation of humic-derived active molecules into compound NPK granulated fertilizers. Main technical difficulties and potential solutions. Chem Biol Technol Agric. 2016;3:18-33.

51. DiDonato $\mathrm{N}$, Chen $\mathrm{H}$, Waggoner $\mathrm{D}$, Hatcher $\mathrm{PG}$. Potential origin and formation for molecular components of humic acids in soils. Geochim Cosmochim Acta. 2017:178:210-22.

52. Piccolo A, Spaccini R, Drosos M, Vinci G, Cozzolini V. The molecular composition of humus carbon: recalcitrance and reactivity in soils. In: Garcia C, Nannipieri P, Hernandez T, editors. The future of soil carbon. London: Academic Press; 2018. p. 87-124.

53. Sutton R, Sposito G. Molecular structure in humic substances: the new view. Environ Sci Technol. 2005;39:9009-15.

54. Piccolo A. The supramolecular structure of humic substances. Soil Sci. 2001;166:810-32.

55. Piccolo A. The supramolecular structure of humic substances: a novel understanding of humus chemistry and implications in soil sciences. Adv Agron. 2002;75:57-134

56. Piccolo A, Cozzolino A, Conte P, Spaccini R. Polymerization of humic substances by an enzyme catalyzed oxidative coupling. Naturwissenschaften. 2000;87:391-4.

57. Cozzolino A, Piccolo A. Polymerization of dissolved humic substances catalyzed by peroxidase. Effects of $\mathrm{pH}$ and humic composition. Org Geochem. 2002;33:281-94.

58. Nuzzo A, Piccolo A. Oxidative and photo-oxidative polymerization of humic superstructures by heterogeneous biomimetic catalysis. Biomacromoecules. 2013;14:1645-52.

59. Reisser M, Purves RS, Schmidt MWl, Abiven S. Pyrogenic carbon in soils: a literature-based inventory and a global estimation of its content in soil organic carbon and stocks. Front Earth Sci. 2016;4:80.

60. Baldock JA, Hawke B, Sanderman J, Macdonald LM. Predicting contents of carbon and its component fractions in Australian soils from diffuse reflectance mid-infrared spectra. Soil Res. 2013;51:577-95.

61. Waggoner DC, Chen H, Willoughby AS, Hatcher PG. Formation of black carbon-like and alicyclic aliphatic compounds by hydroxyl radical initiated degradation of lignin. Org Geochem. 2015;82:69-76.

62. Jeffery S, Verheijen FGA, Van der Felde M, Bastos AC. A quantitative review of the effects of biochar application to soils on crop productivity using meta-analysis. Agric Ecosyst Environ. 2011;144:175-85.
63. Jeffery S, Martijn Bezemer T, Cornelissen G, Kuyper TW, Lehmenn J, Mommer L, Sohi SP, Van de Voorde TFJ, Wardle DA, Van Groenigen JW. The way forward in biochar research: targeting trade-offs between the potential wins. GCB Bioenergy. 2015;7:1-13.

64. Jeffery S, Abalos D, Prodana M, Bastos AC, Van Groenigen JW, Hungate BA, Verheijen F. Biochar boosts tropical but not temperate crop yields. Environ Res Lett. 2017;12:053001.

65. Krull E, Lehmann J, Skjemstad J, Baldock J, Spouncer L. The global extend of black $C$ in soils: is it everywhere? In: Schröder HG, editor. Grasslands: ecology, management and restoration. New York: Nova Science Publishers; 2008. p. 13-7.

66. Jaffe R, Ding Y, Niggemann J, Vähätalo AV, Stubbin A, Spencer RGM, Campell J, Dittmar T. Global charcoal mobilization from soils via dissolution and riverine transport to the oceans. Science. 2013;340:345-7.

67. Dittmar T. The molecular level determination of black carbon in marine dissolved organic matter. Org Geochem. 2008;39:396-407.

68. Malcolm RL. Geochemistry of stream fulvic and humic substances. In: Aiken GR, McKnight DM, Wershaw RL, MacCarthy P, editors. Humic substances in soil, sediment and water. New York: Wiley; 1985. p. 181-209.

69. Ertel JR, Hedges JI, Devol AH, Richey JE, Ribeiro MDNG. Dissolved humic substances in the Amazon river system. Limnol Oceanogr. 1986;31:739-54.

70. Pettersson CP, Allard B, Boren H. River discharge of humic substances and humic-bound metals to the gulf of Bothnia. Estuar Coast Shelf Sci. 1997:44:533-41.

71. Steinberg CEW, Kamara S, Prokhotskaya VY, Manusadzianas L, Karasynova TA, Timofeyev MA, Jie Z, Paul A, Meinelt T, Farjalla VF, Matsuo AYO, Burnison BK, Menzel R. Dissolved humic substances-ecological driving forces from the individual to the ecosystem level? Freshw Biol. 2006;51:1189-210.

72. Krachler R, Krachler RF, Wallner G, Hann S, Laux M, Cervantes Recalde MF, Jirsa F, Neubauer E, von der Kammer F, Hoffmann T, Keppler BK. River-derived humic substances as iron chelators in seawater. Mar Chem. 2015;174:85-93.

73. Wagner S, Ding Y, Jaffe R. A new perspective on the apparent solubility of dissolved black carbon. Front Earth Sci. 2017;5:75.

74. Piccolo A, Conte P. Molecular size of humic substances. Supramolecular associations versus macromolecular polymers. Adv Environ Res. 2000;3:508-21.

\section{Submit your manuscript to a SpringerOpen ${ }^{\circ}$ journal and benefit from:}

- Convenient online submission

- Rigorous peer review

- Open access: articles freely available online

- High visibility within the field

- Retaining the copyright to your article

Submit your next manuscript at $\boldsymbol{\nabla}$ springeropen.com 